\title{
Outcome following valve surgery in Australia: development of an enhanced database module
}

\author{
E. Anne Russell ${ }^{1,2}$, Christopher M Reid ${ }^{2,3}$, Warren F Walsh ${ }^{4}$, Alex Brown ${ }^{5,6}$ and Graeme P Maguire ${ }^{1,2^{*}}$
}

\begin{abstract}
Background: Valvular heart disease, including rheumatic heart disease (RHD), is an important cause of heart disease globally. Management of advanced disease can include surgery and other interventions to repair or replace affected valves. This article summarises the methodology of a study that will incorporate enhanced data collection systems to provide additional insights into treatment choice and outcome for advanced valvular disease including that due to RHD.
\end{abstract}

Methods: An enhanced data collection system will be developed linking an existing Australian cardiac surgery registry to more detailed baseline co-morbidity, medication, echocardiographic and hospital separation data to identify predictors of morbidity and mortality outcome following valve surgery.

Discussion: This project aims to collect and incorporate more detailed information regarding pre and postoperative factors and subsequent morbidity. We will use this to provide additional insights into treatment choice and outcome.

Keyword: Indigenous health, Rheumatic heart disease, Valve surgery, Surgery timing, Outcome indicators

\section{Background}

Valvular heart disease can be congenital or acquired. Acquired disease can be either a result of aging or due to a disease process that damages valves. Management of valvular heart disease can involve a combination of medication, surgical repair or valve replacement with a mechanical or bioprosthetic valve. There were 9,276 heart valve repair or replacement procedures reported in Australia in the year 2013-14 [1]. From a clinician and patient perspective, the aim is to intervene at a time and in a way that ensures the lowest possible operative complications and mortality with the best short and longterm outcome.

A particular cause of acquired valvular heart disease is rheumatic heart disease (RHD). Whilst now rare in high income countries $[2,3]$, it remains a condition of global health importance and an important cause of

\footnotetext{
* Correspondence: graeme.maguire@bakeridi.edu.au

${ }^{1}$ Clinical Research Domain, Baker Heart and Diabetes Institute, 75 Commercial Road, Melbourne, VIC 3004, Australia

${ }^{2}$ School of Epidemiology and Preventive Medicine, Monash University,

Melbourne, VIC, Australia

Full list of author information is available at the end of the article
}

preventable heart disease. In Australia RHD particularly affects Aboriginal and/or Torres Strait Islander peoples (Indigenous Australians) and older non-Indigenous Australians [4, 5].

We have previously analysed data [6] from the Australian and New Zealand Society of Cardiac and Thoracic Surgeons (ANZSCTS) National Cardiac Surgery Database [7] and have identified differences in surgical management for RHD and nonRHD valve disease and for Aboriginal and/or Torres Strait Islander and nonIndigenous Australian patients [5]. In addition we have been able to identify factors associated with outcomes following valve surgery for RHD and nonRHD related valve disease [5, 6, 8].

The details of the Database have been outlined elsewhere [5]. Briefly it is an Australia-wide database for the collection and analysis of the results of cardiac surgery that collates data from Australian hospitals regarding patients who have undergone cardiac surgery, the type of surgery performed, early complications and 30 day mortality. In addition the Database is linked to the Australian National Death Index [9] to assess longer term survival. The Database commenced in 2001 with six surgical centres and currently encompasses 28 Australian sites. 
Table 1 Enhanced peri-operative data collection

\begin{tabular}{|c|c|}
\hline Pre-operative history & ICD 10 code [29] \\
\hline Cerebrovascular diseases & $160-169$ \\
\hline Haemorrhagic & $160-162$ \\
\hline Ischaemic & 163 \\
\hline Transitory ischaemic attack (TIA) & $165-166$ \\
\hline \multirow[t]{6}{*}{ Bleeding } & Eye: $\mathrm{H} 21.00, \mathrm{H} 35.6$ \\
\hline & $\begin{array}{l}\text { Digestive system: K22.11, K22.8, } \\
\text { K25.4, K29.00, K29.01, K29.31, } \\
\text { K29.41, K29.51, K29.61, K29.71, } \\
\text { K29.81, K29.91, K62.5, K92.0, } \\
\text { K92.1, K92.2 }\end{array}$ \\
\hline & $\begin{array}{l}\text { Circulatory system: 185.00, 185.01, } \\
\text { I85.11, N93.0, N92.3, N93.9, N95.0, } \\
\text { R04.0, R04.1 }\end{array}$ \\
\hline & $\begin{array}{l}\text { Genitourinary system: R04.89, } \\
\text { R19.5, R58 }\end{array}$ \\
\hline & $\begin{array}{l}\text { Haemorrhagic disorder due to } \\
\text { circulating anticoagulants: D68.3 }\end{array}$ \\
\hline & $\begin{array}{l}\text { I50.9, 150.0, I50.1, 151.5, I11.0, I11.9, } \\
\text { I13.0, |13.2 }\end{array}$ \\
\hline Heart failure & $\begin{array}{l}\text { O74.2, O75.4, 197.1, 197.8, 125.5, } \\
\text { O29.1, O89.1, 109.81, 127.89 }\end{array}$ \\
\hline Endocarditis & B33.21, 101.1, 109.1, 133, 138, 139, 142.9 \\
\hline \multirow[t]{5}{*}{ Cardiac surgery (including type) } & CABG: 0210 - 0213; \\
\hline & $\begin{array}{l}\text { Valve repair: aortic 02QF, mitral } \\
\text { 02QG, pulmonary } 02 \mathrm{QH} \text {, tricuspid } \\
\text { 02QJ }\end{array}$ \\
\hline & $\begin{array}{l}\text { Valve replacement: aortic } 02 R F \text {, } \\
\text { mitral } 02 R G \text {, pulmonary } 02 R H \text {, } \\
\text { tricuspid 02RJ }\end{array}$ \\
\hline & $\begin{array}{l}\text { Percutaneous/trans-catheter valve } \\
\text { replacement: } 623,628,637,634\end{array}$ \\
\hline & $\begin{array}{l}\text { Percutaneous valvuloplasty: } \\
38270-01,38270-02\end{array}$ \\
\hline \multirow[t]{2}{*}{ Arrhythmia } & $\begin{array}{l}144.0-9,145.0-9,1480-9,149.0-9, \\
197.8,147.0, \text { J84.1, M62.8 }\end{array}$ \\
\hline & $\begin{array}{l}\text { Pacemaker and/or defibrillator } \\
\text { (insertion but not replacement, } \\
\text { removal or adjustment): 38256-00/01 } \\
\text { 38368-00, 38390-00/01/02, 38350-00, } \\
\text { 90202-00/01/02, 38473-00/01, 38470- } \\
\text { 00/01, 38654-00/03, 38353-00, 38393-00 }\end{array}$ \\
\hline
\end{tabular}

Pre-operative and discharge

$\begin{array}{ll}\text { Medication } & \text { Time period } \\ \text { Beta blocker } & \text { Pre-operative, on discharge } \\ \text { ACE Inhibitors } & \text { Pre-operative, on discharge } \\ \text { Angiotensin Receptor Blocker } & \text { Pre-operative, on discharge } \\ \text { Diuretic } & \text { Pre-operative, on discharge } \\ \text { Digoxin } & \text { Pre-operative, on discharge } \\ \text { Warfarin } & \text { Pre-operative, on discharge } \\ \text { NOAC (new oral anticoagulants) } & \text { Pre-operative, on discharge } \\ \text { Aspirin } & \text { Pre-operative, on discharge } \\ \text { Clopidogrel/Prasugrel/Ticagrelor } & \text { Pre-operative, on discharge }\end{array}$

Clinical registries such as this provide a minimum dataset related to the patient, the procedure and outcome. As such they are a valuable resource for informing clinical care, quality assurance activities and for research hypothesis generation. While the Database collects a range of preoperative patient demographic, co-morbidity and outcome data it does not include prior medication use, detailed echocardiography measurements and non-lethal complications beyond 30 days post-procedure.

The medical management of advanced valvular disease can include anti-platelet and anti-coagulant medication, diuretics, angiotensin-converting enzyme (ACE) inhibitors [10], and beta blockers but it is unclear if these agents can influence early and longer term outcomes following surgery. In addition while valvular disease can be complicated by cardioembolism (e.g., stroke) [10] the influence of such a history prior to surgery on outcome, and how this may influence surgical choice, remains unclear.

Existing studies highlight the importance of echocardiographic assessment of the severity of valve disease and preoperative valve and heart function. Such data is currently not collected by the existing Database, in particular, left ventricular endsystolic (LVESD) and enddiastolic (LVEDD) diameter and pulmonary arterial systolic pressure (PASP).

Valve morphology has also been shown to predict outcome for those undergoing RHD-related mitral valve repair including the absence of deformity of the mitral valves leaflets and mitral valve prolapse [11] and maintenance of anterior mitral leaflet mobility [12].

Whilst longer-term survival beyond 30 days for the Database is determined from the National Death Index (NDI) [9], other outcomes are currently captured only to 30 days following surgery and only for the surgical site. Non-lethal longer term outcomes relevant to valve surgery include bleeding and thromboembolic complications, heart failure, endocarditis and reoperation.

Thromboembolic events reported in previous studies for follow-up to 7 years following surgery has ranged from none [13] to $5.9 \%$ [14] and for up to 10 years, 6\% [14] to $24.7 \%$ [15] of mechanical valve replacement recipients and $7 \%$ [16] to $25 \%$ [17] of bioprosthetic valve recipients. Bleeding events have been reported as between $8.8 \%$ [17] and 52.6\% [18]. The long term risk and burden of heart failure following valve surgery is poorly defined and earlier studies have demonstrated a significant risk of subsequent endocarditis [19] .

Reporting of re-operation varies greatly. After a repaired mitral valve, this has ranged from none at 2 years [20] to $90 \%$ at 30 years [21], from $1 \%$ [22] at 9 years for all mitral valve replacements, $3.4 \%$ [14] at 5 years to $12.6 \%$ [23] at 25 years for mechanical valve replacement and 3.6\% at 5 years [14] to $63 \%$ at 25 years [23] for bioprosthetic valve replacements. 
This multicentre, enhanced surveillance system therefore aims to collect short and longer term outcome data to assist in predicting outcomes and providing evidence to inform the development of guidelines to facilitate consistent practice. Utilizing an enhanced data collection system it will collect and incorporate more detailed information regarding pre and postoperative factors at Australian sites that undertake both non-RHD and RHD-related surgery. It will use these more detailed data to provide additional insights into treatment choice and outcome for valve surgery in general and RHD specifically.

Information demonstrated to be important and relevant will be considered for future inclusion in the existing ANZSCTS national cardiac surgery database to assist in predicting outcomes and providing evidence to inform the development of guidelines to facilitate consistent and evidencebased practice in the management of valve disease including for that relating to RHD [10].

\section{Methods}

\section{Population and method of sampling}

Four Australian cardiothoracic surgical sites with significant RHD and non-RHD surgical caseloads representing cases from two different Australian jurisdictions will be included. A random subset of patients having procedures over the preceding ten years, will be chosen from the existing Database.

\section{Sample size}

The sample size will be based on the number required to detect a difference in major adverse prosthesis-related events (MAPE) between bioprosthetic and mechanical valve replacements. MAPE will be defined as a composite outcome of any reoperation, major bleeding, thromboembolic event, or endocarditis during late follow-up [24]. A sample size of 600 patients will be recruited based on an anticipated rate of MAPE over ten years of follow-up of $50 \%$ for mechanical valve replacements and $35 \%$ for bioprosthetic valve replacement [24], a ratio of mechanical to bioprosthetic mitral valve replacements of 2:1 [5], twosided alpha of 0.05 and power of $80 \%$.

\section{Instrumentation}

An enhanced baseline dataset with identical definitions for all data points has been created to standardize data collection. Field names and coding have been defined in line with the existing Database data definitions. The enhanced baseline dataset consists of data shown in Table 1. Pre-operative history will be based on linkage with hospital separation data and with reference to the Massive Transfusion Registry (MTR) [25]. Medication and echocardiography data will be ascertained from the index hospital admission for valve surgery including
Table 1 Enhanced peri-operative data collection (Continued)

\begin{tabular}{|c|c|}
\hline Pre-operative echocardiography & Measurement \\
\hline $\begin{array}{l}\text { Left Ventricular End-Systolic } \\
\text { Diameter }\end{array}$ & $\mathrm{mm}$ \\
\hline $\begin{array}{l}\text { Left Ventricular End-Diastolic } \\
\text { Diameter }\end{array}$ & $\mathrm{mm}$ \\
\hline Left Atrial Diameter & $\mathrm{mm}$ \\
\hline Left Atrial Area & $\mathrm{cm}^{2}$ \\
\hline $\begin{array}{l}\text { Pulmonary Artery Pressure } \\
\text { (maximal tricuspid regurgitant } \\
\text { pressure + estimated right } \\
\text { atrial pressure) }\end{array}$ & $\mathrm{mmHg}$ \\
\hline \multicolumn{2}{|l|}{ Valve data } \\
\hline Mean Gradient & Aortic and mitral valve $(\mathrm{mmHg})$ \\
\hline Peak Gradient & Aortic valve (mmHg) \\
\hline Area & Aortic and mitral valve $\left(\mathrm{cm}^{2}\right)$ \\
\hline Pressure half time & Aortic and mitral valve (ms) \\
\hline Area Planimetery & Mitral valve $\left(\mathrm{cm}^{2}\right)$ \\
\hline Jet Area & Mitral valve $\left(\mathrm{cm}^{2}\right)$ \\
\hline Valve morphology & Aortic and mitral valve \\
\hline Valve abnormality & Tricuspid and pulmonary valve \\
\hline
\end{tabular}

admission history for pre-operative medication, discharge medication and linkage with imaging reporting systems.

In addition to enhanced baseline data collection the project will identify late (more than 30 day) complications potentially associated with valve surgery. In line with pre-surgery morbidity this will be undertaken by using jurisdiction hospital separation data linkage for all hospitalizations and the conditions outlined in Table 1 as well as with reference to the MTR [25]. Outcomes will be recorded and reported according to the Guidelines for reporting mortality and morbidity after cardiac valve interventions [24] with comparisons of major morbidity between mechanical and bioprosthetic valves made using MAPE [26].

Once ethics committee approval is obtained for all sites for the data collection, data will be obtained from surgeon and hospital records for the initial admission and entered onto data collection forms. Permission to access the MTR will be sought to identify all valve surgery patients ( $\geq 18$ years old) who have received at least 5 units of red blood cells (RBCs) within any $4 \mathrm{~h}$ time period.

\section{Analysis plan}

The data collected will be analysed using multivariable, logistic and Cox proportional hazard models to identify independent factors associated with the outcome previously analysed $[5,6]$ and short and long term outcome. This will be undertaken using IBM SPSS Statistics 20 (IBM, New York, USA) and STATA Release 14 (StataCorp LP, Texas, 
USA). Missing data will be noted and assessed for potential bias. Possible missing data could be specific echocardiographic measurements not performed, which would be missing at random and readmission occurring outside the jurisdiction, which may be not missing at random if they are patients from remote areas. Where the patient's residential address is determined to be outside the jurisdiction of the surgical site access to local hospital separation data will be sought. Echocardiographic continuous variables will be stratified as necessary for analysis, using acknowledged cut off values (e.g., mild, mod, severe). The analysis will be assessed to determine if the new data is useful for future incorporation in the national ANZSCTS database for ongoing prospective collection.

This study has been reported following the Strengthening the Reporting of Observational Studies in Epidemiology (STROBE) recommendations [27].

\section{Discussion}

The development of this multicentre, enhanced surveillance systems to collect enhanced baseline and longer term morbidity data will aim to assist in predicting outcomes and providing evidence to inform the development of guidelines to facilitate consistent practice. Added to the existing national cardiac surgery database (Australian and New Zealand Society of Cardiac and Thoracic Surgeons (ANZSCTS)) these data may assist in deciding the most appropriate choice and timing of surgery.

Our analysis of the current database [6] has challenged the findings of earlier studies of surgical outcome in other settings. The finding that neither prior nor new post-operative $\mathrm{AF}$ was found to be an independent predictor of survival in RHD versus non-RHD valve surgery highlights the importance of considering these conditions as separate entities in the setting of valve surgery [28]. Our earlier finding that poorer preoperative clinical status, based on NYHA class, was also not independently associated with longer term survival requires further investigation with the addition of other cardiac and non-cardiac factors that influence NYHA-measured function to assess an independent effect on survival [6]. The addition of medications, echocardiography results and longer-term follow-up will also assist in strengthening the understanding regarding how pre-operative comorbidities and medication use influence outcome with the ultimate aim of enhance the timing and management of patient with advanced valvular heart disease.

\section{Conclusion}

This article summarises the methodology of a project that aims to collect and incorporate more detailed information regarding pre and postoperative factors and nonlethal outcomes at Australian sites that undertake a significant proportion of RHD and non-RHD surgery.
We will use these more detailed data to provide additional insights into treatment choice, timing and outcome.

Information demonstrated to be important and relevant will be considered for future inclusion in an ongoing Australia cardiac surgery registry to assist in predicting outcomes and providing evidence to inform the development of guidelines to facilitate consistent and evidencebased practice in the surgical management of valve disease.

Such data will also be integral to informing future national and international guidelines for the management of advanced valvular heart disease including for RHD as part of the Australian guideline for prevention, diagnosis and management of acute rheumatic fever and rheumatic heart disease [10].

\section{Abbreviations \\ ACE: Angiotensin-converting enzyme inhibitors; ANZSCTS: Australian and New Zealand Society of Cardiac and Thoracic Surgeons; LVEDD: Left ventricular enddiastolic diameter; LVESD: Left ventricular endsystolic diameter; MAPE: Major adverse prosthesis-related events; MUHREC: Monash University Human Research Ethics Committee; NDI: National Death Index; PASP: Pulmonary arterial systolic pressure; RBC: Red blood cell; RHD: Rheumatic heart disease; STROBE: Strengthening the Reporting of Observational Studies in Epidemiology}

\section{Acknowledgments}

E. Anne Russell is supported by an NHMRC Postgraduate Scholarship and an Australian Government Research Training Program Scholarship. Graeme P. Maguire is supported by an NHMRC Practitioner Fellowship Christopher M. Reid is supported by an NHMRC Senior Research Fellowship Alex Brown is supported by a Viertel Senior Medical Research Fellowship. The Australian and New Zealand Society of Cardiac and Thoracic Surgeons (ANZSCTS) National Cardiac Surgery Database Program is funded by the Department of Health Victoria, the Health Administration Corporation and the Clinical Excellence Commission (CEC) NSW, and funding from individual Units.

Supported by NHMRC Centres for Research Excellence to Reduce Inequality in Heart (Grant ID: 1044897) and END RHD (Grant ID: 1080401) and the Victorian Government's OIS Program.

Funding

END RHD Centre of Research Excellence project funding support.

\section{Availability of data and materials}

The data that support the findings of this study are available from Australian and New Zealand Society of Cardiac and Thoracic Surgeons (ANZSCTS) National Cardiac Surgery Database, Monash Centre of Cardiovascular Research and Education in Therapeutics School of Public Health and Preventive Medicine, Monash University but restrictions apply to the availability of these data, which were used under license for the current study, and so are not publicly available. Data are however available from the authors upon reasonable request and with permission of ANZSCTS Research Committee.

\section{Authors' contributions}

EAR drafted the manuscript and will collect the data and perform the statistical analysis. AB helped with revision of the manuscript. CMR helped with revision of the manuscript and will assist with acquisition of data. WW helped with revision of the manuscript. GPM conceived of the study participated in the design of the study, helped to draft the manuscript and will assist with the statistical analysis and interpretation. All authors read and approved the final manuscript.

Competing interests

The authors declare that they have no competing interests. 


\section{Consent for publication}

Permission was obtained from the ANZSCTS National Cardiac Surgery Database Program, managed by The School of Public Health and Preventive Medicine, to use and analyse the data included in the surveillance system.

\section{Ethics approval and consent to participate}

Approval to undertake this study has been provided by the Monash University Human Research Ethics Committee (MUHREC) (CF13/2737 - 2013001472), Central Adelaide Local Health Network Human Research Ethics Committee (CALHNHREC) (R20161023 HREC/16/RAH/435) and Sir Charles Gairdner Hospital Human Research Ethics Committee (SCGHHREC) (HREC Ref: 2016-165).

\section{Author details}

'Clinical Research Domain, Baker Heart and Diabetes Institute, 75 Commercial Road, Melbourne, VIC 3004, Australia. ${ }^{2}$ School of Epidemiology and Preventive Medicine, Monash University, Melbourne, VIC, Australia. ${ }^{3}$ School of Public Health, Curtin University, Perth, WA, Australia. ${ }^{4}$ Prince of Wales Hospital, Randwick, NSW, Australia. ${ }^{5}$ Wardliparingga Aboriginal Research Unit, South Australia Health and Medical Research Institute, Adelaide, SA, Australia. ${ }^{6}$ School of Population Health, University of South Australia, Adelaide, SA, Australia.

Received: 3 August 2016 Accepted: 11 January 2017 Published online: 17 January 2017

\section{References}

1. Australian Institute of Health and Welfare. Hospital care for cardiovascular disease. Canberra, Australia: Australian Government; 2016. [http://www.aihw. gov.au/cardiovascular-disease/hospital-care/]. Accessed 28 May 2016.

2. Bisno A, Butchart E, Ganguly N, Ghebrehiwet T, Lue H, Kaplan E, et al. Rheumatic fever and rheumatic heart disease: report of a WHO Expert Consultation 29 October — 1 November 2001. Geneva: WHO; 2004.

3. Roberts K, Maguire G, Brown A, Atkinson D, Reményi B, Wheaton G, et al. Echocardiographic screening for rheumatic heart disease in high and low risk Australian children. Circulation. 2014:129(19):1953-61.

4. Australian Institute of Health \& Welfare. Rheumatic heart disease and acute rheumatic fever in Australia: 1996-2012. Cardiovascular disease series no. 36. Cat. no. CVD 60. Canbera: Australian Government; 2013. [http://www.aihw. gov.au/publication-detail/?id=60129542750]. Accessed 28 May 2016.

5. Russell E, Tran L, Baker R, Bennetts J, Brown A, Reid C, et al. Valve surgery for rheumatic heart disease in Australia. BMC Cardiovasc Disord. 2014;14:134

6. Russell E, Tran L, Baker R, Bennetts J, Brown A, Reid C, et al. A review of outcome following valve surgery for rheumatic heart disease in Australia. BMC Cardiovasc Disord. 2015:15:103.

7. Australian and New Zealand Society of Cardiac and Thoracic Surgeons (ANZSCTS). Melbourne: CCRE, Monash University; 2010. [http://anzsctsdatabase.org/].

8. Russell EA, Baker RA, Bennetts JS, Brown A, Reid CM, Tam R, et al. Case load and valve surgery outcome in Australia. International Journal of Cardiology. 2016

9. Australian Institute of Health and Welfare. [http://www.aihw.gov.au/nationaldeath-index/2014]. Accessed 28 May 2016.

10. RHDAustralia (ARF/RHD writing group) National Heart Foundation of Australia and the Cardiac Society of Australia and New Zealand. Australian guideline for prevention, diagnosis and management of acute rheumatic fever and rheumatic heart disease. Darwin: Menzies School of Health Research; 2012

11. Choudhary SK, Talwar S, Dubey B, Chopra A, Saxena A, Kumar AS. Mitral valve repair in a predominantly rheumatic population. Long-term results. Tex Heart Inst J. 2001;28(1):8-15.

12. Gupta A, Gharde P, Kumar AS. Anterior mitral leaflet length: predictor for mitral valve repair in a rheumatic population. Ann Thorac Surg. 2010;90(6):1930-3.

13. Gometza B, al-Halees Z, Shahid M, Hatle LK, Duran CM. Surgery for rheumatic mitral regurgitation in patients below twenty years of age. An analysis of failures. J Heart Valve Dis. 1996:5(3):294-301.

14. Galloway AC, Colvin SB, Baumann FG, Grossi EA, Ribakove GH, Harty S, et al. A comparison of mitral valve reconstruction with mitral valve replacement: intermediate-term results. Ann Thorac Surg. 1989;47(5):655-62.

15. De Santo LS, Romano G, Della Corte A, Tizzano F, Petraio A, Amarelli C, et al. Mitral mechanical replacement in young rheumatic women: analysis of long-term survival, valve-related complications, and pregnancy outcomes over a 3707-patient-year follow-up. J Thorac Cardiovasc Surg. 2005;130(1):13-9.

16. Yau TM, El-Ghoneimi YA, Armstrong S, Ivanov J, David TE. Mitral valve repair and replacement for rheumatic disease. J Thorac Cardiovasc Surg. 2000;119(1):53-60.

17. McLean A, Waters M, Spencer E, Hadfield C. Experience with cardiac valve operations in Cape York Peninsula and the Torres Strait Islands, Australia. Med J Aust. 2007;186(11):560-3.

18. Kuwaki K, Kawaharada N, Morishita K, Koyanagi T, Osawa H, Maeda T, et al. Mitral valve repair versus replacement in simultaneous mitral and aortic valve surgery for rheumatic disease. Ann Thorac Surg. 2007;83(2):558-63.

19. Baskerville CA, Hanrahan BB, Burke AJ, Holwell AJ, Remond MG, Maguire GP. Infective endocarditis and rheumatic heart disease in the north of Australia. Heart Lung Circ. 2012;21(1):36-41.

20. Bakir I, Onan B, Onan IS, Gul M, Uslu N. Is rheumatic mitral valve repair still a feasible alternative?: indications, technique, and results. Tex Heart Inst J. 2013;40(2):163-9.

21. DiBardino DJ, ElBardissi AW, McClure RS, Razo-Vasquez OA, Kelly NE, Cohn LH. Four decades of experience with mitral valve repair: analysis of differential indications, technical evolution, and long-term outcome. J Thorac Cardiovasc Surg. 2010;139(1):76-83. discussion -4.

22. Ho HQ, Nguyen VP, Phan KP, Pham NV. Mitral valve repair with aortic valve replacement in rheumatic heart disease. Asian Cardiovasc Thorac Ann. 2004;12(4):341-5.

23. Sarralde J, Bernal J, Llorca J, Ponton A, Diez-Solorzano L, Gimenez-Rico J, et al. Repair of rheumatic tricuspid valve disease: predictors of very long-term mortality and reoperation. Ann Thorac Surg. 2010;90(2):503-8.

24. Akins CW, Miller DC, Turina MI, Kouchoukos NT, Blackstone EH, Grunkemeier $\mathrm{G}$, et al. Guidelines for reporting mortality and morbidity after cardiac valve interventions. J Thorac Cardiovasc Surg. 2008;135:732-8.

25. Transfusion Outcomes Research Collaborative. Massive Transfusion Registry (MTR) Monash University, Melbourne, Australia. 2016. [Available from: http://www.torc.org.au/mtr]

26. Kulik A, Be'dard P, Lam B-K, Rubens FD, Hendry PJ, Masters RG, et al. Mechanical versus bioprosthetic valve replacement in middle-aged patients. Eur J Cardiothorac Surg. 2006;30:485-91.

27. von Elm E, Altman DG, Egger M, Pocock SJ, Gøtzsche PC, Vandenbroucke $J P$, et al. The Strengthening the Reporting of Observational Studies in Epidemiology (STROBE)statement: guidelines for reporting observational studies. J Clin Epidemiol. 2008:61:344-9.

28. Russell E, Maguire G, Bennetts J, Baker R, Reid C, Tran L. The burden and implications of preoperative atrial fibrillation in Australian heart valve surgery patients. Heart Lung Circ. 2016;25(8):e111.

29. ICD10Data.com. 2016 ICD-10-CM Diagnosis Codes. 2016. [Available from: http://www.icd10data.com//CD10CM]. Accessed 28 May 2016.

\section{Submit your next manuscript to BioMed Central and we will help you at every step:}

- We accept pre-submission inquiries

- Our selector tool helps you to find the most relevant journal

- We provide round the clock customer support

- Convenient online submission

- Thorough peer review

- Inclusion in PubMed and all major indexing services

- Maximum visibility for your research

Submit your manuscript at www.biomedcentral.com/submit
) Biomed Central 